\title{
Business modelling revisited: the configuration of control and value
}

\author{
Pieter Ballon \\ IBBT-SMIT, Vrije Universiteit Brussel (Belgium) \& TNO-ICT (The Netherlands) \\ pieter.ballon@vub.ac.be
}

Final Draft, to be published in INFO: The Journal of Policy, Regulation and Strategy for Telecommunications, Information and Media, 9, 5 (2007), 6-19.

\section{INTRODUCTION}

The concept of a business model as a way to describe the "architecture of a business" is closely linked to the rise of Internet-based e-commerce (Hawkins, 2001). The additional sales channel offered by the on-line environment spurred firms to devise new ways of interacting with their customers, in the expectation that more direct or valuable ways of interaction would become possible. Early approaches to business modelling therefore focused on the selection of the most appropriate virtual channels and revenue models (see e.g. Slywotzky, 1996; Timmers, 1998; Weill \& Vitale, 2001). These 'new economy' approaches have been fairly well documented, although they were often lacking conceptual clarity. As a rule, they highlighted typologies and taxonomies of new business models, according to specific revenue models (e.g. on-line auctions), or according to specific virtual channels or value propositions (e.g. virtual marketplaces).

As the 'new economy' fever subsided, the attention of business model literature shifted towards the integration of virtual activities into the real-world marketplace. Also, another ICT sector was now facing the redesign of its 'business architecture', i.e. the mobile telecommunications industry. In this industry, interest in the concept of business models had been fuelled by the (partial) unbundling of technical functions and economic roles, caused mainly by increasing technological modularity and regulatory pressure, and the expectation of a range of new valueadded telecommunications services. In the wake of the success of i-mode in Japan, a success that was mainly credited to its innovative business model, it became clear that for mobile telecommunications, the provision of new services through appropriate cooperation and coordination models (including revenue sharing models) was the main business model issue (Methlie \& Pedersen, 2001; Ballon et al, 2002; Lindmark et al, 2004). From then onwards, the main questions to be solved by new business models increasingly became those connected with shifting firm boundaries, the level of vertical and horizontal integration in the industry and the complex provision of new services.

Meanwhile, business modelling methodologies were also evolving, to include more than the identification of typologies. One approach was to consider business modelling as the development of an unambiguous ontology that can serve as the basis for business process modelling and business case simulations (see e.g. Pigneur, 2002; Faber et al, 2003; Osterwalder, 2004). This corresponds with related technology design approaches (TINA-C, 1997; Gordijn \& Akkermans, 2001) aimed at the mapping of business roles and interactions onto technical modules, interfaces and information streams.

As a result of all this, the focus of business modelling has gradually shifted from the single firm to networks of firms, and from simple concepts of interaction or revenue models to extensive concepts encompassing the value network, the functional architecture, the financial model, and the eventual value proposition made to the user (Faber et al, 2003; Ballon, 2005). The subject of business 
modelling has evolved from the positioning and/or marketing strategy of a single firm to the outset of the entire network, its interrelations and inherent hierarchies (Linder \& Cantrell, 2000). Business modelling is also moving from a static to a dynamic approach, considering various influences on business model viability, business model evolution and the place of business models in the product or service lifecycle (Bouwman \& Mac Innes, 2006; Dittrich \& VandenEnde, 2006).

Recent work on information intermediaries in open business models (Chesbrough 2003; Chesbrough et al, 2006), on intermediaries and gatekeepers in two-sided markets (Jullien, 2004) and on platform leaders in modular markets (Gawer \& Cusumano, 2002) has consolidated the shifting preoccupation from single-firm revenue generation towards multi-firm control and interface issues. As such, the guiding question of a business model has become "Who controls the value network and the overall system design" just as much as "Is substantial value being produced by this model (or not)". In fact, we will argue in this paper that it is precisely the alignment of control and value parameters that is of most relevance to business modelling.

It has been argued that the business model is one of the few integrative strategy models that could unify disparate strategic perspectives such as the resource-based view and industrial organisation, and thereby substantially improve strategy theory (Hedman \& Kalling, 2001). However, several authors have stated that there is a strong theoretical deficit in the business modelling literature regarding the operationalisation of its concepts and the link with established strategy, management and economic theory (Porter, 2001; Lambert, 2006).

A number of authors writing on the topic of business models have already begun to remedy this, but often they still refer mainly to literature dealing specifically with business models, instead of also taking established, non-business model related theories into account. The aim of this paper is to provide a starting point for a further, theoretically grounded operationalisation, by revisiting the existing business model literature itself as well as the most relevant streams of general management and economic theory dealing with the issues of control and value creation in networks, i.e. strategic management, innovation management, industrial organisation, resource-based theory, and network economics (see also Amit \& Zott, 2001; Keen \& Qureshi, 2006).

Obviously, the integration of viewpoints from these various strands of thought is risking the same reproaches of heterogeneity and heterodoxy as are justifiably made against most existing business modelling frameworks. However, by focusing on the key central concepts of control and value, this paper attempts to make at least the first steps towards an integrative framework. This focus strongly echoes pre-business model writings on the 'political economy' of designing new ICT (see e.g. Mulgan, 1991; Mansell, 1993; Mansell \& Silverstone, 1996). Literature on the political economy of ICT design stresses that control configurations, power relationships and different forms of bias pervade ICT design, and profoundly influence the outcome in terms of individual, societal and economic value. Consequently, it argues that the design of ICT products, services and systems should be informed by and analysed according to this basic premise. In other strands of thought, the same preoccupations with governance and value can be recognised, albeit often in a less direct manner (see e.g. Teece et al, 1997; Cox, 1999).

It is the objective of this paper to demonstrate in what way business modelling literature and practice as it has evolved over the last decade, is offering a tool to model the relationship between control over and value of new ICT products and services and to analyse the scope for choice available to designers and users for the 
(re)configuration of these parameters. The paper proposes a set of parameters for the design and analysis of business models, and identifies the crucial trade-offs involved.

\section{BUSINESS MODEL DESIGN PARAMETERS}

The business model can be operationalised through a set of crucial design parameters that need to be addressed when designing a business model for new or improved ICT products or services. In general, it can be stated that a business model is feasible if there is a "fit" (Bouwman, 2003) between the main design parameters that have to be taken into account in order to construct, differentiate and assess business models.

The bulk of business model literature up to the present day has made an attempt to identify such parameters for categorizing and analyzing business models, usually under terms such as "business model dimensions", "business model building blocks", or "business model elements". As pointed out by Dubosson-Torbay et al (2001), most business model literature limits itself to identifying only two critical parameters or dimensions for differentiating and analysing business models. These include functional integration and degree of innovation (Timmers, 1998); economic control (both hierarchical and self-organizing) and value integration (Tapscott et al., 1999), type of relationships and degree of externality (Amami \& Thévenot, 2000), and power of sellers and buyers (Pigneur, 1999). Pateli \& Giaglis (2003), in their overview of the 20 most cited sources in business modelling, add to this overview a number of other, commonly found, sets of business model parameters, i.e. revenue and position in value chain; interaction pattern and value chain integration; core activities and price - value balance; and sourcing.

Based on such parameters, many business model authors propose a taxonomy of basic types of business models: from 5 for Tapscott et al (1999) to about 30 for Rappa (2001). As argued by Dubosson-Torbay et al (2001), the diversity in parameters as well as in classes of business models shows the inadequacy of a unique classification scheme. Therefore, they propose to use a multi-category approach and to accept that a business model can and should be positioned with regard to several dimensions, in a web of classification schemes covering various domains. In effect, their business model framework is divided into four principal components: (1) the products and services a firm offers, representing a substantial value to a target customer (value proposition), and for which he is willing to pay; (2) the relationship the firm creates and maintains with the customer, in order to satisfy him and to generate sustainable revenues; (3) the infrastructure and the network of partners that are necessary in order to create value and to maintain a good customer relationship; and (4) the financial aspects that can be found throughout the three former components, such as cost and revenue structures.

Using the same four business model domains, this has been systematized into nine business model parameters or "building blocks" by Osterwalder (2004). They are the value proposition, the target customer, the distribution channel, the customer relationship, the value configuration, capabilities, partnership, cost structure, and the revenue model. Another commonly cited set of business model design parameters ("elements") can be found in Weil \& Vitale (2001). They distinguish the strategic objective and value proposition, the sources of revenue, critical success factors, core competencies, customer segments, channels, and the IT infrastructure. The approaches of Weil \& Vitale and Dubosson-Torbay et al, as well as Osterwalder's ontology demonstrate the validity of and need for a multiparameter analysis of business models situated within a domain or level structure. 
However, for the purpose of business model design, it can be argued that they are too focused on individual firms' corporate decisions, as well as being quite disparate and heterogeneous, comprising almost the entire spectrum of a firm's internal and external strategy.

Haaker et al (2004) consider critical design parameters specifically for (multistakeholder) mobile services and as a result do extend their view towards the level of the value network. They define a critical design issue as a design variable that is not nominal in nature (such as availability of a network or of investments), but one that is perceived to contribute to the viability of the studied business model. Based on a set of mobile service case-studies they identify four critical design issues in the service domain, i.e. targeting, creating value, branding, and customer retention, and five critical design issues in the technical domain, i.e. security, quality of service, system integration, accessibility and management of user profiles. Similarly the authors found four critical design issues in the organizational domain, i.e. partner selection in order to acquire critical resources and capabilities, network openness, complexity and governance and four critical design issues in the financial domain, i.e. pricing, division of investments, division of costs and revenues, and valuing contributions and benefits.

While being structured more logically than previous frameworks, the set of design parameters put forward by Haaker et al (2004) is still rather disparate in nature. Some of the parameters seem to be quite particular to the cases studied, while others appear to be generally applicable to product or service design. Also, most of their design parameters allow a very wide range of options, resulting in an almost infinite number of potential business models. In order to avoid such problems, the next section proposes an alternative design framework that is more grounded in established theory, aligned according to a restrained number of key issues, and that limits the scope of options to the main trade-offs encountered.

\section{BUSINESS MODEL DESIGN FRAMEWORK}

The business model design and analysis framework presented here follows the multi-parameter approach by defining four levels on which business models operate, and by identifying three critical design parameters on each level. They refer not solely to a single firm, but to the entire network of stakeholders involved in producing and delivering the product, service or system in question. This is done in order to transcend the narrow scope that was observed in many traditional business modelling approaches. However, given the very complex multi-actor environments under scrutiny there is also a need to safeguard the workability of the business modelling process. This can be done by:

- Focusing on criticality and uncertainty when selecting parameters;

- Allowing only generally applicable parameters, and

- Focusing on the core dimensions and trade-offs most relevant to ICT business models and that are affecting the other business model building blocks considered.

To identify these core dimensions and trade-offs, we revisited the basic twodimensional schemata that underlie most of the earlier business model literature. Analysing the schemata mentioned above, and also referring to the political economy viewpoint expressed earlier, the vast majority of them stress the dimensions of value creation and capture on the one hand (which relates to aspects such as the value proposition and the financial model), and the dimension of control on the other (relating to the outset of the value network and the functional 
architecture). Thus, it can be argued that basically, a business model captures the major value-related and control-related issues that need to be addressed when innovating products or services, and the interrelationships between them.

Adapting the domain approach introduced by Faber et al (2003), we distinguish between four domains or 'levels' of business modelling: the level of the value network (i.e. the architecture of actors and roles in the future marketplace), the level of the functional model (i.e. the architecture of technical components in the future technological system), the level of the financial model (i.e. the architecture of financial streams determining the future business case), and the level of the value proposition (i.e. the architecture or general outline of the future product or service).

At the value network level, three basic design concepts are needed, i.e. roles, actors and relationships. A role is a distinct value adding activity within the value network, that potentially can exist as a commercial entity in the marketplace, with its own cost and revenue balance (comparable to a value adding activity within a linear value chain, see Porter, 1985). An actor is a commercial entity active in the marketplace, integrating one or more roles. A relationship is the expression of an interaction between roles or actors. It may consist of a market transaction, a longterm contract, a company-internal arrangement, a trust relationship etc. The most basic design parameters for the value network therefore are:

- The relative weight (hierarchies) between the actors. We call this the specific combination of assets;

- The way in which roles are combined by actors. We call this the level of vertical integration;

- The relationship between the producing actor(s) and the consuming actor(s). We call this customer ownership.

At the functional architecture level, we are dealing with technical systems composed of at least one building block (or module), governed by certain rules (or intelligence), and that interwork (or not) with other technical systems. So at the most basic level, a functional architecture is defined by

- The modules and interfaces between modules;

- The distribution of intelligence within the system, and

- The interoperability with other systems.

At the financial level, the most basic building blocks are costs for setting up and running the service or product, the revenues gained from it, and the way these are shared between actors. Therefore we distinguish:

- The cost (sharing) model;

- The revenue model;

- The revenue sharing model.

Finally, at the value proposition level, the most basic choices to make are:

- How to position the new service or product vis-à-vis existing services and products;

- Whether a 'finished' value proposition is made at all, or whether to allow substantial customer involvement in constructing the value of the service;

- What the main value proposed to the market primarily consists of. 
In summary, the selected business model design parameters are listed in the table below. Control parameters are listed in columns A and B, while value related parameters are listed in columns $\mathrm{C}$ and $\mathrm{D}$.

Table $N^{\circ} 1$-Business Model Design Parameters

\begin{tabular}{|l|l|l|l|}
\hline \multicolumn{2}{|c|}{ CONTROL PARAMETERS } & \multicolumn{1}{c|}{ VALUE PARAMETERS } \\
$\begin{array}{c}\text { Network } \\
\text { Parameters }\end{array}$ & $\begin{array}{c}\text { B. Functional } \\
\text { Architecture } \\
\text { Parameters }\end{array}$ & $\begin{array}{c}\text { C. Financial } \\
\text { Model } \\
\text { Parameters }\end{array}$ & $\begin{array}{c}\text { D. Value } \\
\text { Proposition } \\
\text { Parameters }\end{array}$ \\
\hline $\begin{array}{l}\text { A1. Combination } \\
\text { of Assets }\end{array}$ & B1. Modularity & $\begin{array}{l}\text { C1. Cost } \\
\text { (Sharing) Model }\end{array}$ & D1. Positioning \\
\hline $\begin{array}{l}\text { A2. Vertical } \\
\text { Integration }\end{array}$ & $\begin{array}{l}\text { B2. Distribution } \\
\text { of Intelligence }\end{array}$ & $\begin{array}{l}\text { C2. Revenue } \\
\text { Model }\end{array}$ & $\begin{array}{l}\text { D2. User } \\
\text { Involvement }\end{array}$ \\
\hline $\begin{array}{l}\text { A3. Customer } \\
\text { Ownership }\end{array}$ & $\begin{array}{l}\text { B3. } \\
\text { Interoperability }\end{array}$ & $\begin{array}{l}\text { C3. Revenue } \\
\text { Sharing Model }\end{array}$ & $\begin{array}{l}\text { D3. Intended } \\
\text { Value }\end{array}$ \\
\hline
\end{tabular}

The following sections define and briefly examine these twelve parameters (for an extensive treatment, see Ballon, 2006). Their scope, relevance to business modelling, and the essential trade-offs and interdependencies related to each parameter, are outlined, leaving ample room for elaboration and adjustment to specific cases, which should also be part of any business modelling process. In general, only the main business model design choice, related to value creation and capture, and/or to control, is identified here, and is grounded within current thinking in strategic management, innovation management, industrial organisation, resource-based theory, and network economics.

\section{CONTROL PARAMETERS}

\section{A. Combination of Assets}

Competence-based strategic management literature is slowly acknowledging the importance of combinative capabilities, which can be defined as a firm's ability to combine internal and external resources to create new resource combinations that are rare, valuable, hardly imitable and non-substitutable (Koruna, 2004). It is precisely this combination of internal and external assets that has been identified recently as the key strategic issue for survival in open innovation environments, and as one of the crucial determining factors of successful business models (Chesbrough, 2003).

Successful combination of assets is closely related to leveraging a structurally strong position within a value network. As Iansiti \& Levien (2004) argue, one of the most common fallacies regarding open innovation environments is that they are constituted by all peers. Instead, important and even vital hierarchies are present in such environments. Ballon \& Hawkins (2003) define different partner types in the value network that may contribute to the shaping of a particular business model: structural, contributing, and supporting partners (ranging from greater to lesser actor power, depending on the kind of resources they contribute), thus identifying the nature of interdependencies in a given network and the strategic position of actors within the network. Wehn et al (2005) match these types to, respectively, essential, network-specific, and generic resource contributions to value creation, ranging from greater to lesser relevance to value creation in the network, based on resource characteristics. Together, these concepts may be used to typify the power structure among the actors in a value network and to set the scene for an analysis of its impact on a particular business model. 
In essence, it can be stated that if essential resources are concentrated with one actor, while the other actors only have generic resources, i.e. if the value network is composed of one structural partner while the other partners are supporting partners, assets are strongly concentrated. At the other extreme, if essential resources are spread evenly across multiple partners, assets are distributed.

\section{B. Vertical Integration}

The second choice associated with business model (re)design relates to the scope of the firm in terms of markets and industries in which it competes. It is in fact far from clear what the optimal scope of the firm is for operating in a technologybased, high-risk, growing and internationalising industry such as the ICT industry (see e.g. Robertson \& Langlois, 1994; Kranton \& Minehart, 2000). Robertson and Langlois (1994) argue that the uncertainty associated with radical and systemic innovations generally favours co-ordination and integration of some kind, either through innovative networks or conglomerates (usually in the introductory stage of an innovation) or through vertically integrated firms (as the product life-cycle reaches more maturity). As standardisation increases, the technological incentive to collaborate generally becomes less strong, and firms may decide to vertically integrate some of their network partners. However, under certain circumstances, disintegration may also be an option in this phase (see e.g. Fontenay \& Hogendorn, 2005).

A range of authors, in dealing with the particularities of the internet and the ICT industry in general, have argued that current digital networks (including the internet), by significantly lowering barriers to worldwide exchange of information and trade, are enabling direct contact between economic agents to such a degree that extensive disintermediation may take place, while at the same time lowering transaction costs to the extent that vertical unbundling of the ICT industry is a viable alternative to integrated supply. These assertions open up a range of choices to be taken by organisations in terms of their positioning and vertical integration strategies, even if post-dot.com literature has tended to tone down the idea of almost unlimited choices faced by organisations doing business electronically by pointing at historical, industry- or market-specific contexts limiting the range of options open to these organisations (Lehr, 1998; Hawkins \& Verhoest, 2002).

In any case, it is clear that the scope of the firm, or the level of vertical integration, within a particular value network, directly affects the business model. This choice ranks highly amongst the most cited parameters in the whole of the business model literature (Pateli \& Giaglis, 2003). The essential trade-off that can be identified here is between integrated and disintegrated value chains and networks.

\section{Customer Ownership}

The third business model parameter included in this framework refers to customer relationship in general and customer ownership in particular, i.e. the establishment of direct relations with end customers. This is also related to access to key information about customers, products, markets and costs. On a value network level, the question which partner assumes the direct commercial relationship with the customer, is of equal, if not higher importance. While it is in essence the objective of any actor to position itself as closely to the customer as possible, the most suited actor to take the customer ownership is the actor that can act as guarantor of the value proposition(s) present in the service or product (Lee, 2006).

Several levels of intensity of customer ownership can be distinguished, depending upon issues such as establishing a trusted reputation, customer relationship management, marketing and branding, and customer lock-in. Dalziel (2005), for instance, stresses proximity to the customer, which extends the notion of customer ownership to both geographical proximity and the understanding of the customers' 
needs and behaviour, as a key concept that governs relationships between collaborating firms. The author stresses that proximity to the customer is not necessarily in hands of the "central firm", but can also be in the hands of "niche firms", such as intermediaries, resellers, system integrators and so on.

In general, the business model trade-off is to characterise customer ownership as intermediated (i.e. operated by intermediaries that are positioned between the actor that produces the good or service in question) versus direct (i.e. operated directly by the actor that produces the good or service in question).

\section{Modularity}

The fourth crucial business model design parameter reviewed here is modularity. Modularity in a technical sense refers to the design of systems and artefacts as sets of discrete modules that connect to each other via predetermined interfaces. These modules are independent in the sense that changing one module does not alter another module (Baldwin \& Clark, 2000). The key promise modularity offers is the possibility of delivering a continuous stream of incremental innovations around a common technological platform, or product architecture. Advantages could include enhanced product variety and mass customization, rapid upgradability to meet changing customer needs, exploitation of economies of scale and scope at the platform level, increased pace and decreased costs of parallel experimentation, decreased coordination costs of innovative projects, and ease of recombination of divisional resources to cope with changing product-market domains (Brusoni \& Fontana, 2004).

Modularity is a crucial design parameter profoundly affecting the nature of systems, products and services, the pace of innovation, and the structure of firms, value networks, and markets (Baldwin \& Clark, 2000; Cebon et al, 2002; Ulrich, 1995). However, there is no automatic link between adopting a modular product design strategy and the adoption of a modular organization (Ernst, 2005). Also, it is the assertion of various authors that system integrators (Prencipe et al, 2003) or platform leaders (Gawer \& Cusumano, 2002) are still required to coordinate diversified knowledge bases.

In terms of functional architecture, the main trade-off identified is the choice between modular design and production on the one hand versus integrated or interdependent design and production on the other hand.

\section{E. Distribution of Intelligence}

A vital business model design parameter is the distribution of intelligence. In ICT systems, this refers to the particular distribution of processing power, control and (management of) functionality across the system in order to deliver a specific application or service. In telecommunications, the shift from a centralized network topology towards a more decentralised one started twenty years ago with the introduction of the Intelligent Network as a concept characterized by distributed intelligence and an architecture with standard network interfaces in which services were to be provided independently of the physical structure of the network. Analyses emphasizing the political economy of network evolution have demonstrated the link with specific commercial interests in an increasingly liberalised telecommunications market, attempts to impose restrictions on access and struggles to gain control over the system (Mansell, 1993).

Recent research confirms that the 'addition' and specific configuration of intelligence in the network remains a key driver for network and business evolution alike (Reda, 2004). Regarding the impact on networked collaboration between organisations, historical analysis tends to stress the intra-domain relations between business architectures, business model architectures, application architectures, and 
ICT platform architectures (Aerts et al, 2004). It can be stated that the distribution of intelligence is a powerful architectural concept influencing functional design but at the same time impacting on business and organisational design in many networked sectors of the economy. The main trade-off in this respect is between centralised and distributed intelligence in system architectures.

\section{F. Interoperability}

Interoperability refers to the ability of technological systems to directly exchange information and services with other systems, and to the interworking of services and products originating from different sources. Interoperability choices determine to an important degree the functional architecture, and also exert influence on value network configuration (e.g. integration, customer ownership choices) and the value proposition towards the customer (e.g. through lock-in strategies and network externalities).

Blind (2005) notes that interoperability with the products, services or systems of competitors is ambivalent. Dominant players have little interest in interoperability with competing products, because especially price competition will drive down their profits (Besen \& Farrell 1994), and because interoperability may reduce lockin effects. In contrast, small companies or companies entering the market should have a stronger interest to provide products which are interoperable with the products of the incumbents or the dominant players in order to use their so called installed base of users.

The main trade-off identified here is the one between interoperable and noninteroperable (or stand-alone) architectures. Usually, however, some kind of interoperability is opted for. A strongly related trade-off is the one between open (i.e. publicly available) or closed (i.e. proprietary) solutions. Cebon et al (2002) point to the relationship between open and closed architectures and the issues of control, network externalities, and speed of developments. Open architectures breed network externalities but yield very little control to one player, unless it can control the standards defining the open architecture and innovate faster than the competition (Garud and Kumaraswamy, 1995).

\section{VALUE PARAMETERS}

\section{A. Cost sharing model}

This refers to the anticipated costs, necessary for the design, development and exploitation of a product or service, and more precisely the way these are shared amongst the actors involved. Cost theory distinguishes several types of costs. The most relevant costs in this context relate to investments (including capital expenditure and $R \& D$ costs) and the anticipated operational expenses. At the time of business model design, most knowledge will be about up-front investments. Two related concepts of costs that are relevant here are sunk costs, i.e. up-front costs that cannot be recovered, and marginal costs, i.e. costs that are incurred when producing additional increments to the existing production level. The relation between up-front investments (which are often also sunk costs) and operational costs is closely related to economies of scale and scope, and thus to horizontal and vertical integration. It is the 'unbalance' between very high up-front costs and close-to-zero marginal costs involved in the production and exploitation of digital content that has lead authors to describe various ICT industries as natural monopolies (Shapiro \& Varian, 1999).

When dealing with complementary products or services (see also below), as is generally the case in the ICT sector, so-called coordination failures and hold-up problems may occur. These refer to market failures in the sense that no (implicit or 
explicit) agreement can be found over which actor needs to make the necessary investments. It can be stated that the most important trade-off in this respect is whether investments are concentrated with one actor, or distributed over various actors.

\section{B. Revenue Model}

Ranging from Timmers' (1998) taxonomies including e-shops and e-auctions to Rappa's (2001) business model classification including subscription models (users are charged a periodic fee to subscribe to a service) and utility models (based on metering usage, or a pay as you go approach), the revenue model is, next to vertical integration, the design parameter that 'traditional' business model literature has been most concerned with, to the point of even identifying business models with revenue models.

Clearly, choices and trade-offs for this parameter are dependent upon the application domain in question. In the case of (digital) content services, there is the traditional trade-off between direct (i.e. paid by the consumer) and indirect (i.e. paid by the advertiser, or by public subsidies) revenue models. As Prasad et al (2003) argue, advertising and media share a symbiotic relationship. Media providers have to balance the revenue from advertising and subscription, since consumers generally dislike fees as well as advertising: both high subscription prices and large numbers of advertisements turn consumers away. Prasad et al also remark that this trade-off, along with the potential of contemporary electronic media to inexpensively design and offer several price-advertising choices, offers a means for media providers to segment their audiences, so that the business model design choice is not restricted to setting a single price and advertising level. This is because of differing opportunity costs of viewers when watching advertisements. A secondary trade-off is between content-based and transport-based revenue models (see e.g. Methlie \& Pedersen, 2005).

\section{Revenue sharing model}

The revenue sharing model refers to agreements on whether and how to share revenues among the actors involved in the value chain. Literature on the Japanese success of i-mode and on the global success of iPod and the iTunes music store provide salient examples of the importance of revenue sharing models for the success of business models (see e.g. Lindmark et al, 2004).

The main trade-off that can be identified is the one between having a revenue sharing model in place (i.e. distributing the revenues over several actors), and not having a revenue sharing model (i.e. concentrating revenues with a single actor, and working through direct market mechanisms, licenses etc. between actors). A secondary trade-off is between content-oriented revenue sharing and transportoriented revenue sharing models (Methlie \& Pedersen, 2005).

\section{Positioning}

Usually, the positioning of products and services refers to marketing issues including branding, identifying market segments, establishing consumer trust, identifying competing products or services, and identifying the most relevant attributes of the product or service in question. Here, we emphasize choices regarding intended complementarity and substitutability.

There is a large theoretical body on composite goods, complements and supplements. In the ICT sector, many products and services can be said to be perfect and imperfect complements as well as (often imperfect) substitutes (see e.g. Varian, 2003). Usually, literature takes the relative positioning in terms of complementarity and substitutability between products and services as a given. Still, evidence shows that there is often even considerable choice involved. For 
instance, it is one of the main tenets of the convergence literature that ICT goods and services emanating from complementary industries are increasingly being designed as substitutes, by adding features or creating synergies early on in the design phase.

Positioning is a complex issue for which many choices and trade-offs can be identified. The most basic one seems to be whether to position a product or service as a complement to a particular set of existing products and services, or rather as a substitute to them. It should be noted that there is a significant cognitive problem in objectively defining the set of products and services that the new or improved product or service is positioned against, so this parameter refers to the intended set of substituted or complementary products and services.

\section{E. Customer involvement}

Customer involvement is another, increasingly important, design parameter for ICT products and services business models. Reference can be made to case studies on dominant applications such as SMS, peer-to-peer filesharing, web services, for which customer involvement in shaping the value proposition has been the crucial business model determinant. Referring to literature, Von Hippel (1988) was among the first authors to stress the role of lead users in product and service innovation. Also, the domestication strand of literature (Silverstone \& Haddon, 1996) needs to be mentioned, that emphasizes the active roles users play in assigning meaning and value to new products and services.

As ICTs constitute so-called general purpose technologies (Bresnahan \& Trajtenberg, 1995), ICT products or services can be used by various actors, including end users, to construct new products and services. In this way, users become producers of products and services in their own right, and are empowered to play various roles within value networks (Von Hippel, 2005). The main trade-off that can be identified in this context is the one between high (meaning, in all or most stages) and low (meaning, in few or no stages) levels of customer involvement in the value creation process.

\section{F. Intended Value}

The final business model parameter lists the primary attributes that the product or service is intended to possess, and that together constitute the intended customer value. From a business planning perspective, three strategies to achieve optimal user value can be distinguished (Treacy \& Wiersema, 1993):

- Operational excellence: Through cost-advantages the price of the product/service drops below a level where it can attract a critical mass of consumers;

- Product leadership: The service or product offered is of premium quality and innovative, and comes at a premium price;

- Customer intimacy: The consumer sees the advantage of a more intimate relationship with the provider of a set of products/services, and is wiling to relinquish an amount of privacy in exchange for a custom-made solution.

Since these three strategies in many instances are conflicting, it is assumed that business planning should conduct a trade-off analysis in order to prioritize the optimal strategic mix. This should be done with maximum customer value as the objective. Intrinsic as well as extrinsic attributes (network effects) need to be considered in this respect. For a specific product or service, the trade-offs will be service, product or application domain specific. They relate to the operational excellence (price) / product leadership (quality) versus customer intimacy (lock-in) 
trade-off referred to above. Typical more specific trade-offs include reliability versus flexibility, quality versus price, and security versus ease-of-use.

\section{CONCLUSION AND FURTHER WORK}

In order to clarify the often confusing and sibylline business model debate, this paper has conceptualised business model design as the reconfiguration of control and value, and has proposed an analytical framework for making explicit the scope for choice when designing a business model for ICT services, products and systems. It has taken into account recent directions in business model research and practice, i.e. the establishment of ontologies, the inclusion of various levels of business model design as well as the focus on the entire value network of stakeholders. Furthermore, it has attempted to ground the framework with respect to the prevalent literature on strategic management, innovation management, industrial organisation, resource-based theory, and network economics.

The figure below summarizes the main parameters and basic trade-offs into a matrix that can be used for the design and analysis of any ICT business model. It is the assertion that any business model needs to address these basic parameters, either implicitly or explicitly.

Table $N^{\circ} 2-$ The Business Model Design Matrix

\begin{tabular}{|c|c|c|c|c|c|c|c|}
\hline \multicolumn{4}{|c|}{ CONTROL PARAMETERS } & \multicolumn{4}{|c|}{ VALUE PARAMETERS } \\
\hline \multicolumn{2}{|c|}{$\begin{array}{l}\text { Value Network } \\
\text { Parameters }\end{array}$} & \multicolumn{2}{|c|}{$\begin{array}{c}\text { Functional } \\
\text { Architecture } \\
\text { Parameters }\end{array}$} & \multicolumn{2}{|c|}{$\begin{array}{l}\text { Financial Model } \\
\text { Parameters }\end{array}$} & \multicolumn{2}{|c|}{$\begin{array}{c}\text { Value Proposition } \\
\text { Parameters }\end{array}$} \\
\hline \multicolumn{2}{|c|}{ Combination of Assets } & \multicolumn{2}{|c|}{ Modularity } & \multicolumn{2}{|c|}{ Cost (Sharing) Model } & \multicolumn{2}{|c|}{ Positioning } \\
\hline Concentrated & Distributed & Modular & Integrated & Concentrated & Distributed & Complement & Substitute \\
\hline \multicolumn{2}{|c|}{ Vertical Integration } & \multicolumn{2}{|c|}{$\begin{array}{l}\text { Distribution of } \\
\text { Intelligence }\end{array}$} & \multicolumn{2}{|c|}{ Revenue Model } & \multicolumn{2}{|c|}{ User Involvement } \\
\hline Integrated & Disintegrated & Centralised & Distributed & Direct & Indirect & High & Low \\
\hline \multicolumn{2}{|c|}{ Customer Ownership } & \multicolumn{2}{|c|}{ Interoperability } & \multicolumn{2}{|c|}{$\begin{array}{l}\text { Revenue Sharing } \\
\text { Model }\end{array}$} & \multicolumn{2}{|c|}{ Intended Value } \\
\hline Direct & Intermediated & Yes & No & Yes & No & $\begin{array}{l}\text { Pricel } \\
\text { Quality }\end{array}$ & Lock-in \\
\hline
\end{tabular}

Further work includes making explicit the interdependencies between the design parameters and the extension of this model in a more prospective and predictive sense. However, if the framework presented here does not allow yet to speculate on the eventual successfulness of a particular business model, it already seems clear that for a business model to be feasible, the control variables on the one hand, and the value variables on the other hand, need to be strategically aligned.

\section{ACKNOWLEDGEMENTS}

Part of the research for this paper was performed in the framework of the Quality of Experience Project of the Interdisciplinary Institute for BroadBand Technology (IBBT) of Flanders, Belgium. The author wishes to thank two anonymous reviewers for their helpful comments on an earlier draft of this paper. 


\section{REFERENCES}

Aerts, A., Goossenaerts, J., Wortmann, J. \& D. Hammer (2004) "Architectures in Context: On the Evolution of Business, Software, and ICT-Platform Architectures", Information and Management, Vol.41/6, 781 - 794 .

Amami M. \& J. Thévenot (2000) “L'Internet marchand: caractérisation et positionnements stratégiques", Systèmes d'Information et Management, 5 (1), 5-40.

Amit, R. \& C. Zott (2001) "Value Creation in e-business", Strategic Management Journal, 22, 493-520.

Baldwin, C. \& K. Clark (2000) Design Rules: The Power of Modularity. MIT Press, Cambridge.

Ballon, P. (ed.) (2005) Best Practices in Business Modelling for ICT Services. Delft: TNO Report no. 33561.

Ballon, P. (2006) "Business Modelling for ICT Products and Services: Conceptual Framework and Design Criteria", in: Limonard, S. (ed.) Integrated Methodological Framework. Freeband B@Home Deliverable, ref. Freeband/B@Home/D2.8.

Ballon, P. \& Hawkins, R. (2003) From Business Models to Value Networks. Delft: TNO/STB Working Paper.

Ballon, P., Helmus, S., van de Pas, R. \& H.-J. van de Meeberg (2002) "Business Models for Next-Generation Wireless Services", Trends in Communications, Vol. 9: Mobile Internet, 7-29.

Besen, S. \& J. Farrell (1994) "Choosing How to Compete: Strategies and Tactics in Standardization", Journal of Economic Perspective, 8(2), 117-131.

Blind, K. (2005) "Interoperability of Software. Demand and Solutions", in: Panetto, Hervé (Ed.) Interoperability of Enterprise Software and Applications. London: Hermes Science Publ., 2005, 199-210.

Bouwman, H. (2003). State of the art on Business Models, Enschede: Telematica Instituut, Freeband B4U D3.2 Report.

Bouwman, H. \& I. MacInnes (2006) "Dynamic Business Model Framework for Value Webs", Proceedings of the 39th Annual Hawaii International Conference on System Sciences (HICSS '06), 04-07 January 2006.

Bresnahan, T. \& M. Trajtenberg (1995) "General purpose technologies 'engines of growth'?”, Journal of Econometrics, Vol. 65, No. 1, 83-108.

Brusoni, S. \& R. Fontana (2005) Modularity as an Entry Strategy: The invasion of new niches in the LAN equipment industry. CESPRI Working Papers 171, Universita' Bocconi, Milano, Italy, July 2005.

Cebon, P., Hauptman, O., \& C. Shekhar (2002) Industries in the making: product modularity, technological innovation, and the product life cycle. Melbourne Business School, mimeo.

Chesbrough, H. (2003). Open Innovation - The New Imperative for Creating and Profiting from Technology. Harvard Business School Press

Chesbrough, H., Vanhaverbeke, W. \& J. West (eds.) (2006) Open Innovation: Researching a New Paradigm. Oxford: Oxford University Press.

Cox, A. (1999) "Power, value and supply chain management", Supply Chain Management: An International Journal, Vol 4, Issue 4 (Oct 1999), 167-175.

Dalziel, M. (2005) “Asymmetric Interfirm Relations”, Proceedings of the DRUID 10th Anniversary Summer Conference, Copenhagen, Denmark, June 27-29, 2005.

Dittrich, K. \& J. VandenEnde (2006) "Organizational forms for the development of new broadband services: a dynamic model for the degree of integration between collaborating firms", Paper presented at the DRUID Summer Conference, Copenhagen, Denmark, 10-12 June, 2006.

Dubosson-Torbay, M., Osterwalder, A. \& Y. Pigneur (2001) "eBusiness Model Design, Classification and Measurements", Thunderbird International Business Review, 2001. 
Ernst, D. (2005) "Limits to Modularity: Reflections on Recent Developments in Chip Design”, Industry and Innovation, Vol. 12, No. 3, 303-335, September 2005.

Faber, E., Ballon, P., Bouwman, H., Haaker, T., Rietkerk, O. \& M. Steen (2003)

"Designing Business Models for Mobile ICT Services", Proceedings of the 16th Bled Ecommerce conference, Bled, Slovenia, 9-11 June 2003.

Fontenay, A. de and C. Hogendorn (2005). Entry and Vertical Disintegration in Networks. Working Paper. http://chogendorn.web.wesleyan.edu/

Garud, R. and Kumaraswamy, A. (1995) "Technological and organizational designs to achieve economies of substitution”, Strategic Management Journal, Vol. 16, 93-110.

Gawer, A. \& Cusumano, M. (2002) Platform Leadership: How Intel, Microsoft, and Cisco Drive Industry Innovation. Boston: Harvard Business School Press.

Gordijn, J. \& J.M. Akkermans (2001) "e3-value: Design and Evaluation of e-Business Models", IEEE intelligent Systems, special issue on e-business, Vol. 16, No. 4, 11-17.

Haaker, T., Bouwman, H., \& Faber, E. (2004) "Customer and network value of mobile services: Balancing requirements and strategic interests", in: R. Agarwal, L. Kirsch, \& J. I. DeGross (Eds.), Proceedings of the 25th international conference on Information systems (ICIS 2004), Washington, D.C.: Association for Information Systems, 1-14.

Hawkins, R. (2001). The 'Business Model' as a Research Problem in Electronic Commerce. STAR (Socio-economic Trends Assessment for the digital Revolution) IST Project, Issue Report No. 4, July 2001, SPRU - Science and Technology Policy Research. Hawkins, R. and Verhoest, P. (2002). 'A transaction structure approach to assessing the dynamics and impacts of 'business-to-business' electronic commerce'. Journal of Computer-Mediated Communication, 7(3), April 2002.

Hedman, J. \& T. Kalling (2001) The Business Model: A Means to Understand the Business Context of Information and Communication Technology. Institute of Economic Research: Working Paper Series, School of Economics and management, Lund University, 2001/9.

Iansiti, M., Levien, R. (2004). The Keystone Advantage - What the New Dynamics of Business Ecosystems Mean For Strategy, Innovation and Sustainability. Harvard Business School Press.

Jullien, B. (2004) Two-Sided Markets and Electronic Intermediation. IDEI Working Papers 295, Institut d'Économie Industrielle (IDEI), Toulouse.

Keen, P. \& S. Qureshi (2006) “Organizational Transformation through Business Models: A Framework for Business Model Design”, Proceedings of the 39th Hawaii International Conference on System Sciences 2006.

Koruna, S. (2004) "Leveraging knowledge assets: combinative capabilities - theory and practice”, R\&D Management 34, 5, 505-516.

Kranton, R. \& D. Minehart (2000) "Networks versus Vertical Integration”, RAND Journal of Economics, The RAND Corporation, vol. 31(3), 570-601.

Lambert, S. (2006) "A Business Model Research Schema”, Proceedings of the 19th Bled eConference, Bled, Slovenia, June 5 - 7, 2006.

Lee, A. (2006) "Business System Architecture process (BSAP): The Reference Meta Model”, WWI Workshop, International Conference of Mobile Business 2006 (ICMB 06), Copenhagen, Denmark, 26-27 June 2006.

Lehr, William (1998) "Understanding Vertical Integration in the Internet”, ITC draft paper prepared for Euro CPR' '98 Conference, Venice, February 1998.

Linder, J. C., Cantrell, S. (2000). Changing Business Models: Surveying the Landscape. Institute for Strategic Change, Accenture.

Lindmark, S., Bohlin, E. \& E. Andersson (2004) "Japan's mobile internet success story facts, myths, lessons and implications", info, Vol. 6, 6, 348-358.

Mansell, R. (1993) The New Telecommunications: A Political Economy of Network Evolution. London et al: Sage Publications.

Mansell, R. \& R. Silverstone (1996) “Introduction”, in: Mansell, R. \& R. Silverstone (eds.) Communication by Design: The Politics of Information and Communication Technologies. Oxford: Oxford University Press, 1-14. 
Methlie, L. \& P. Pedersen (2001) "Understanding business models in mobile commerce", Paper presented at Wireless World Research Forum 3, Stockholm, Sweden, September 2001.

Methlie, L. \& P. Pedersen (2005) "Network effects and intrinsic attributes of mobile services: Mapping perceived service values on business model choices", Paper presented at the Hong Kong Mobility Roundtable, 2005, Hong Kong, June, 1-3.

Mulgan, G. (2001) Communication and Control: Networks and the New Economies of Communication. Cambridge: Polity Press.

Osterwalder A. (2004) The Business Model Ontology: A Proposition in a Design Science Approach. Ph.D. thesis 2004, HEC Lausanne.

Pateli, A. \& G. Giaglis (2003) "A Framework for Understanding and Analysing e-Business Models", Proceedings of the 16th Bled Electronic Commerce Conference eTransformation, Bled, Slovenia, June 9-112003.

Pigneur, Y. (1999) "Les technologies de l'information changent l'art du possible”, Genève, 21 ème siècle, 21 défis et 21 talents pour les relever, 1999, 80-89.

Pigneur, Y. (2002) “An Ontology for m-business models”, in: S. Spaccapietra et al. (Eds.) Conceptual Modeling - ER 2002, Tampere, Lecture Notes in Computer Science, 2503, October 2002.

Porter, M. (1985) Competitive Advantage: Creating and Sustaining Superior Performance. New York: Free Press.

Porter, M. (2001) Strategy and the Internet, Harvard Business Review, 79 (3): pp. 62-78.

Prasad, A., Mahajan, V. \& B. Bronnenberg (2003) "Advertising versus pay-per-view in electronic media”, International Journal of Research in Marketing, 20 (2003), 13-30.

Prencipe, A., Davies, A. \& M. Hobday (Eds.) (2003) The Business of Systems Integration. Oxford: Oxford University Press.

Rappa, M. (2001). Managing the digital enterprise - Business models on the Web. http://digitalenterprise.org/models/models.html

Reda, R. (2004) "Intelligence in Communication Systems Evolution, Trends and Business Opportunities", Proceedings of the IFIP International Conference, INTELLCOMM 2004, Bangkok, Thailand, November 23-26, 2004, 1-15.

Robertson, P. L. \& R. Langlois (1994) Innovation, Networks, and Vertical Integration, Industrial Organization. Economics Working Paper 9406006, Archive EconWPA.

Shapiro, C. \& H. Varian (1999). Information Rules: A Strategic Guide to the Network Economy. Cambridge: Harvard Business School Press.

Silverstone, R. \& L. Haddon (1996) "Design and the Domestication of Information and Communication Technologies: Technical Change and Everyday Life", in: Mansell, R. \& R. Silverstone (eds.) Communication by Design: The Politics of Information and Communication Technologies. Oxford: Oxford University Press, 44-74.

Slywotzky, A. J. (1996). Value Migration - How to Think Several Moves Ahead of the Competition. Harvard Business School Press, Boston, MA.

Tapscott, D. (Ed.) (1999) Creating Value in the Network Economy. Harvard Business School Press.

Teece, D., Pisano, G. \& A. Shuen (1997) "Dynamic capabilities and strategic management”, Strategic Management Journal, Vol. 18, 7, 509-533.

Timmers, P. (1998) "Business Models for Electronic Markets", Journal on Electronic Markets, 8(2), p. 3-8.

TINA-C (Telecommunications Information Networking Architecture Consortium) (1997) TINA Business model and reference points. TINA-C report.

Treacy, M. \& F. Wiersema (1993) “Customer Intimacy and other value disciplines", Harvard Business Review, 71(1), 84-93.

Ulrich, K. T. (1995) “The Role of Product Architecture in the Manufacturing Firm”, Research Policy, 24, 419-440. 
Varian, H. (2003) Economics of Information Technology. Raffaele Mattioli Lecture, delivered at Bocconi University, Milano, Italy, on November 15-16, 2001 and the Sorbonne on March 6, 2003.

Von Hippel, E. (1988) The Sources of Innovation, New York: Oxford University Press.

Von Hippel, E. (2005) Democratizing Innovation. Cambridge, MA: The MIT Press.

Wehn de Montalvo, U.,E.A.M. van de Kar, C.F. Maitland (2005) "Resource based interdependencies in value networks for mobile e-services", International Journal of eBusiness Research, 1(3), 1-20.

Weill, P. \& Vitale, M.R. (2001) Place to Space: Migrating to eBusiness Models. Harvard Business School Press, Boston. 